\title{
Gai3 nuclear translocation causes irradiation resistance in human glioma cells
}

\author{
Shang Cai ${ }^{1, *}$, Ya $\mathrm{Li}^{2, *}$, Jin-Yu Bai ${ }^{3, *}$, Zhi-Qing Zhang ${ }^{2, *}$, Yin Wang2, Yin-Biao Qiao ${ }^{4}$, \\ Xiao-Zhong Zhou ${ }^{3}$, Bo Yang ${ }^{4}$, Ye Tian', Cong Cao ${ }^{2}$ \\ ${ }^{1}$ Department of Radiotherapy and Oncology, The Second Affiliated Hospital of Soochow University, Suzhou, China \\ ${ }^{2}$ Institute of Neuroscience, Soochow University, Suzhou, China \\ ${ }^{3}$ Department of Orthopedics, The Second Affiliated Hospital of Soochow University, Suzhou, China \\ ${ }^{4}$ Department of Surgery, The Third Hospital affiliated to Soochow University, Suzhou, China \\ *Co-first authors
}

Correspondence to: Bo Yang, email: dryangbosz@163.com

Ye Tian, email: tianyesuzhoua163@163.com, dryetian@126.com

Cong Cao, email: caocong@suda.edu.cn

Keywords: glioma, irradiation, Gai3, DNA-PKCS

Received: March 13, 2017 Accepted: March 30, $2017 \quad$ Published: April 11, 2017

Copyright: Cai et al. This is an open-access article distributed under the terms of the Creative Commons Attribution License (CC-BY), which permits unrestricted use, distribution, and reproduction in any medium, provided the original author and source are credited.

\section{ABSTRACT}

We have previously shown that Gai3 is elevated in human glioma, mediating Akt activation and cancer cell proliferation. Here, we imply that Gai3 could also be important for irradiation resistance. In A172 human glioma cells, Gai3 knockdown (by targeted shRNAs) or dominant-negative mutation significantly potentiated irradiation-induced cell apoptosis. Reversely, forced over-expression of wild-type or constitutively-active Gai3 inhibited irradiation-induced A172 cell apoptosis. Irradiation in A172 cells induced Gai3 translocation to cell nuclei and association with local protein DNA-dependent protein kinase (DNA-PK) catalytic subunit. This association was important for DNA damage repair. Gai3 knockdown, depletion (using Gai3 knockout MEFs) or dominant-negative mutation potentiated irradiation-induced DNA damages. On the other hand, expression of the constitutively-active Gai3 in A172 cells inhibited DNA damage by irradiation. Together, these results indicate a novel function of Gai3 in irradiation-resistance in human glioma cells.

\section{INTRODUCTION}

Glioma is the most common primary central nervous system (CNS) malignancy. It is a major health threat [1-3]. Each year, glioma will cause significant cancerrelated death [1-3]. Postoperative irradiation and temozolomide (TMZ) chemotherapy are the standard clinical treatments for glioma [4-6]. Yet, the overall survival has not been significantly improved over the past decades [4-6]. The prognosis of high-grade glioma, including glioblastoma, has been poor [1, 6, 7]. One possible cause is the overwhelming resistance to current irradiation (and chemotherapy) $[1,6,7]$.

$\mathrm{G}$ protein $\alpha$ inhibitory subunit (Gai) couples with GPCRs (G-protein coupled receptors) [8] to inhibit adenylate cyclase (AC) [8]. Recently, our group [9-11] and others [12] have discovered an un-anticipated function of Gai: transducing Akt-mTOR signaling by receptor tyrosine kinases (RTKs). We have previously found that Gai protein was required for EGFR (epidermal growth factor receptor)- and FGFR (fibroblast growth factor receptor)-induced activation of Akt signaling [9-11]. In our model, Gai could couple with EGFR/FGFR to activate the adaptor protein (i.e. Gab1), which mediates activation of downstream Akt signaling [9-11].

There are at least three Gai subunits, including Gai1, Gai2 and Gai3 [8]. Our recent study has shown that Gai3 is over-expressed in human glioma cells, which is required for Akt activation and cancer cell proliferation [11]. The results of the current study indicate that Gai protein could also be important for irradiation resistance. 


\section{RESULTS}

\section{Silencing Gai3 sensitizes irradiation-induced glioma cell death}

In order to study the potential function of Gai3 in irradiation resistance, shRNA strategy was applied. As described previously [11], two distant lentiviral shRNAs against non-overlapping sequence of Gai3 were utilized. The two were named as "Gai3 shRNA-a" and "Gai3 shRNA-b". As shown in Figure 1A, the two Gai3 shRNAs silenced Gai3 in human glioma A172 cells. These Gai3silenced A172 cells and control cells were treated with various degree (0-10 Gy) of irradiation. Trypan blue staining assay results in Figure 1B demonstrated that A172 cells with Gai3 shRNA were significantly more sensitive to irradiation than the control A172 cells. Irradiation led to significantly more A172 cell death after Gai3 knockdown (Figure 1B). The IC-50 of irradiation, or the intensity that kills $50 \%$ of A172 cells, decreased from over 6 Gy to less than 1.5 Gy after Gai3 silence (Figure 1B). MTT assay results (Figure 1C) and colony formation assay (Figure 1D) further confirmed that Gai3 knockdown significantly facilitated irradiation (5 Gy)-induced killing of A172 cells. Notably, Gai3 shRNA-b was more efficient in silencing Gai3 (than Gai3 shRNA-a, Figure 1A), it was also more dramatic in sensitizing irradiation-induced A172 cell death (Figure 1B-1D). Notably, Gai3 silence alone also induced minor/moderate A172 cell death (Figure 1B-1D), which was also reported early [11].

The results above suggested that Gai3 might be important in irradiation resistance. To further support this hypothesis, Gai3 knockout ("KO") mouse embryonic fibroblasts (MEFs) [11] were utilized.. Trypan blue assay results in Figure 1F and MTT assay results in Figure 1G confirmed that Gai3 KO MEFs were significantly more vulnerable to irradiation (5 Gy) than the wild-type ("WT") MEFs. For instance, 96 hours after irradiation ( 5 Gy), $63.3 \pm 8.6 \%$ of WT MEFs were still alive, yet only $23.6 \pm 2.6 \%$ of Gai3 KO MEFs were trypan blue negative (Figure 1F). Together, these results demonstrate that Gai3 silence or depletion could lead to irradiation-sensitization in glioma cells.

\section{Silencing Gai3 sensitizes irradiation-induced glioma cell apoptosis}

It is known that irradiation kills cancer cells via inducing cell apoptosis $[13,14]$. We next wanted to know the potential effect of Gai3 in the process. In line with our previous studies $[10,11,15,16,17]$, various apoptosis assays were applied, including Histone DNA apoptosis ELISA assay, TUNEL intensity assay and Annexin V staining assay. As expected, irradiation treatment in A172 cells induced significant apoptosis, which was evidenced by increase of Histone DNA apoptosis ELISA OD
(Figure 2A), TUNEL intensity OD (Figure 2B) and percentage of Annexin $\mathrm{V}$ positive cells (Figure 2C). Remarkably, Gai3 silence by targeted shRNA dramatically facilitated irradiation-induced A172 cell apoptosis (Figure 2A-2C). Gai3 shRNA alone (no irradiation) also induced minor A172 cell apoptosis (Figure 2A-2C). Gai3 KO MEFs were again utilized. As demonstrated, irradiation $(5 \mathrm{~Gy})$ induced significantly more apoptosis in Gai3 KO MEFs (as compared to WT MEFs, Figure 2D and 2E). For instance, after irritation, $17.6 \pm 1.5 \%$ of Gai3 KO MEFs were apoptotic (Annexin V positive), compared to only $6.3 \pm 1.9 \%$ in WT MEFs (Figure 2E). Basal apoptosis activation was slightly higher in Gai3 KO MEFs than in the WT MEFs (Figure 2D and 2E) [11].

\section{Exogenous Gai3 over-expression in A172 cells cause irradiation resistance}

Based on the results above, we would speculate that Gai3 over-expression shall cause irradiation resistance. Thus, wild-type ("WT") Gai3 construct (see our previous study $[10,11]$ ) was introduced to A172 cells. Via puromycin selection, the stable cells with the construct were established. Western blotting assay results in Figure 3A confirmed the expression of exogenous Gai3 (Flag-tagged) in the stable cells. Significantly, irradiationinduced A172 cell death (MTT OD reduction, Figure 3B) and apoptosis (Histone DNA ELISA OD increase, Figure 3C) were dramatically inhibited in Gai3-overexpressed A172 cells. Thus, Gai3 over-expression led to irradiation resistance in glioma cells.

\section{Irradiation sensitivity is altered with Gai3 mutation in A172 cells}

Next, mutation strategies were employed to potentially alter the activity of Gai3 in A172 cells. As discussed in our previous studies $[9,11]$, the dominantnegative Gai3 (DN-Gai3), which has a conserved Gly (G) residue replaced by $\mathrm{Thr}(\mathrm{T})$ in the $\mathrm{G} 3$ box $[9,10,11]$, was introduced to A172 cells (Figure 4A). The DN-Gai3 shall compete with the wt-Gai3 for binding with other proteins $[18,19]$. Significantly, irradiation-induced A172 cell death (Figure 4B) and apoptosis (Figure 4C) were remarkably potentiated with the Gai3 DN mutation. On the other hand, a constitutively-active Gai3 (Q204L, CAGai3) [9] was transfected to A172 cells, and stable cells were again established. Results in Figure 4A confirmed CA-Gai3 (Flag-tagged) expression in the stable A172 cells (Figure 4A). Remarkably, A172 cells with CAGai3 were protected from irradiation (Figure 4B and 4C). Irradiation-induced A172 cell death (Figure 4B) and apoptosis (Figure 4C) were largely inhibited after CAGai3 expression. These results together indicate that change of Gai3 activity could alter irradiation sensitivity in A172 cells. 


\section{Irradiation induces Gai3 nuclear translocation and association with DNA-PKes}

It is known that irradiation induces DNA damages, which leads to subsequent cell apoptosis [20-22]. DNA repair mechanisms could however repair damaged DNA, causing irradiation resistance [20-22]. One of major protein complex for DNA repair is DNA-dependent protein kinase (DNA-PK). DNA-PK is primarily composed of the $460-\mathrm{kDa}$ catalytic subunit (DNA$\mathrm{PKcs})$ and the $\mathrm{Ku}$ hetero-dimer (Ku-70 and $\mathrm{Ku}-80)$ [23, 24]. Intriguingly, we showed that irradiation treatment in A172 cells induced Gai3 translocation to nuclei (Figure 5A). Basal Gai3 level in nuclei, as expected, was few (Figure 5A). Following the irradiation, the Gai3 level in the cell nuclei was significantly increased (Figure 5A), indicating nuclear translocation. Remarkably, the coimmunoprecipitation assay results showed that nucleitranslocated Gai3 formed a complex with local protein DNA-PKcs (Figure 5B). Considering that DNA-PKcs is critical for DNA damage repair [20-22], we proposed that Gai3 could also be important for DNA repair. Indeed, we found that irradiation-induced DNA-damage, tested by $\gamma$-H2AX increase [25-27], was significantly potentiated with Gai3 silence (by "Gai3 shRNA-b") or DN mutation in A172 cells (Figure 5C). Reversely, expression of CAGai3 inhibited DNA damages by irradiation (Figure 5D). Further, as compared to the WT MEFs, an increase of
A

A172

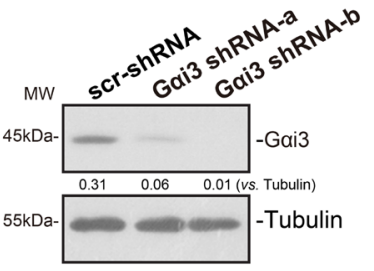

C

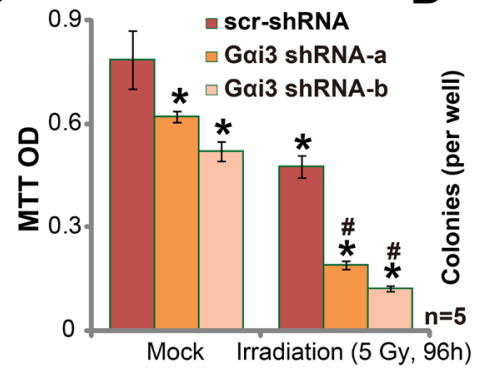

B
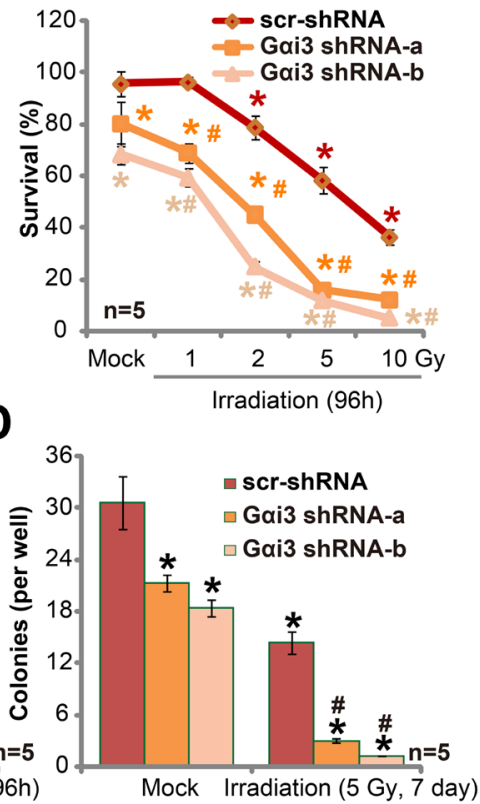

E

MEFs

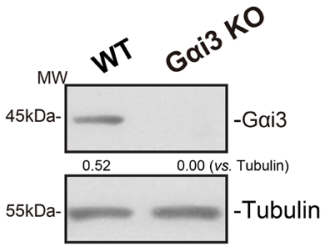

$\mathbf{F}$

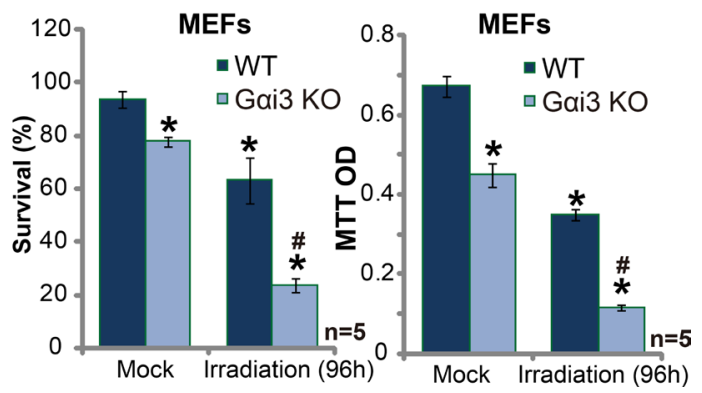

Figure 1: Silencing Goi3 sensitizes irradiation-induced glioma cell death. Western blotting tested expression of listed proteins in stable A172 cells with Gai3 shRNA ("-a/-b") or scramble control shRNA ("scr-shRNA") (A); A172 cells were also subjected to irradiation (at indicated intensity) and cultured for indicated time, listed assays were performed to test cell survival/death (B-D). Expression of listed proteins in wild-type (WT) and Gai3 knockout (KO) MEFs was shown (E); MEFs were irradiated (5 Gy) and cultured for additional 96 hours. Afterwards, MEFs were subjected to trypan blue staining assay (F) and MTT assay (G). For all the assays, the exact same number of viable cells of different genetic background was initially plated into each well (Same for all Figures). Same set of lysate samples were run in sister gels (A and E). "Mock" stands for un-irradiated cells (Same for all Figures). " $n=5$ " means five replicate wells (Same for all Figures). Bars stand for mean $\pm \mathrm{SD}$ (Same for all Figures). * $p<0.05 v s$. "Mock" of "scr-shRNA" A172 cells or WT MEFs. ${ }^{\prime} p<0.05 v s$. "Irradiation" of "scr-shRNA" A172 cells (B-D) or WT MEFs (F and G). Experiments in this figure were repeated three times, with similar results obtained. 
$\gamma$-H2AX staining (indicating DNA damage) was noticed in irradiated Gai3 KO MEFs (Figure 5E). Notably, basal DNA-damage or $\gamma-\mathrm{H} 2 \mathrm{AX}$ staining was unchanged by above Gai3 genetic modifications (Figure 5C-5E). Together, our results imply that irradiation induces Gai3 nuclear translocation and association with DNA-PKcs, which apparently is crucial for DNA-damage repair and irradiation resistance.

\section{DISCUSSION}

The results of this study suggest that Gai3 could be a key resistance factor of irradiation in glioma cells. Gai3 depletion significantly potentiated irradiation-induced cell apoptosis. On the other hand, forced over-expression of Gai3 inhibited irradiation-induced A172 cell apoptosis. Meanwhile, irradiation sensitivity in A172 cells was
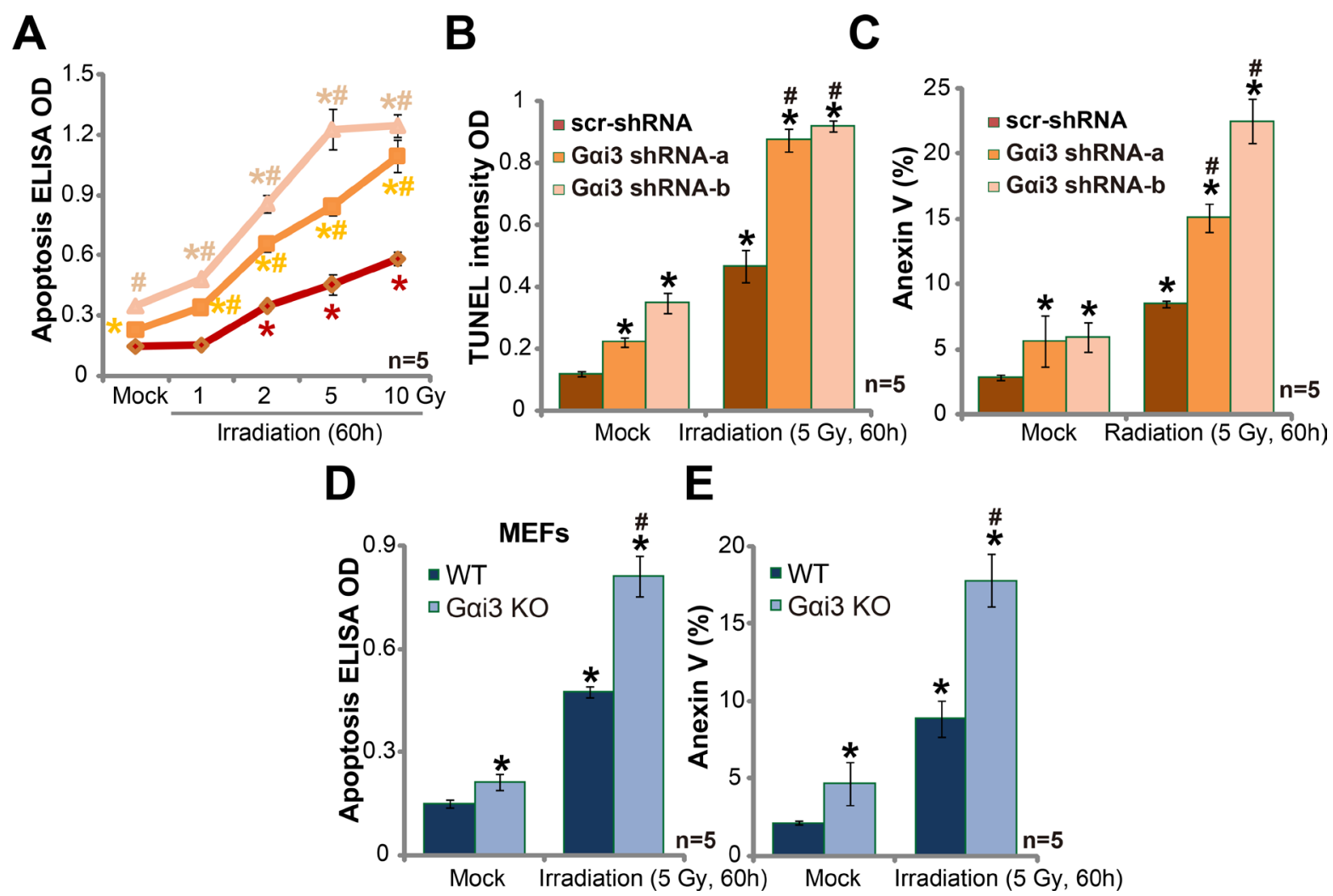

Figure 2: Silencing Gai3 sensitizes irradiation-induced glioma cell apoptosis. A172 cells with Gai3 shRNA ("-a/-b") or scramble control shRNA ("scr-shRNA") (A-C), as well as wild-type (WT) and Gai3 knockout (KO) MEFs (D-E) were treated with irradiation (at indicated intensity) and cultured for additional 60 hours; Afterwards, cell apoptosis was tested by the listed assays. ${ }^{*} p<0.05$ vs. "Mock" of "scr-shRNA" A172 cells (A-C) or WT MEFs (D-E). " $p<0.05$ vs. "Irradiation" of "scr-shRNA" A172 cells (A-C) or WT $\operatorname{MEFs}(\mathrm{D}-\mathrm{E})$.
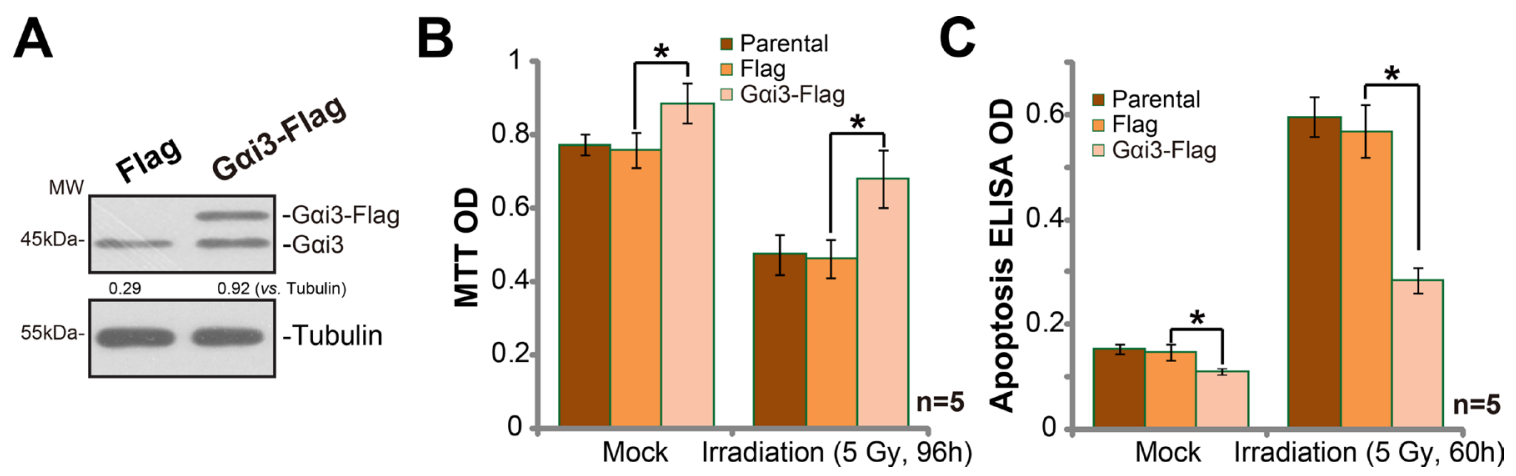

Figure 3: Exogenous Gai3 over-expression in A172 cells cause irradiation resistance. (A) Western blotting analysis results showed expression of Gai3 (endogenous and exogenous) in stable A172 cells with the Flag-tagged Gai3 or empty vector (pSuper-puroFlag, "Flag"). Cells were treated with irradiation (5 Gy) and cultured for indicated time; Cell death (MTT OD reduction, (B)) and apoptosis (Histone DNA ELISA assay, $(\mathbf{C})$ ) were tested. "Parental" stands for control parental A172 cells. * $p<0.05$. 
potentiated when expressing DN-Gai3, but was reduced after CA-Gai3 expression. Mechanistic study further showed that Gai3 translocation to nuclei, which was important for DNA damage repair. These results together imply that Gai3 over-expression in human glioma cells could be a key irradiation-resistance factor.

Irradiation-induced DNA damage will initiate DNA repair pathway [20-22]. There are at least two major signaling pathways that could possibly repair DNA damages, including the non-homologous end joining (NHEJ) pathway and the homologous recombination (HR) pathway [20-22]. In the process of NHEJ, Ku70/80 proteins will sense and bind to ends of the DNA termini in a structure-specific manner, which is followed by the recruitment and activation of DNA-PKcs [28, 29]. Afterwards, DNA ligase IV-XRCC4 complex is recruited
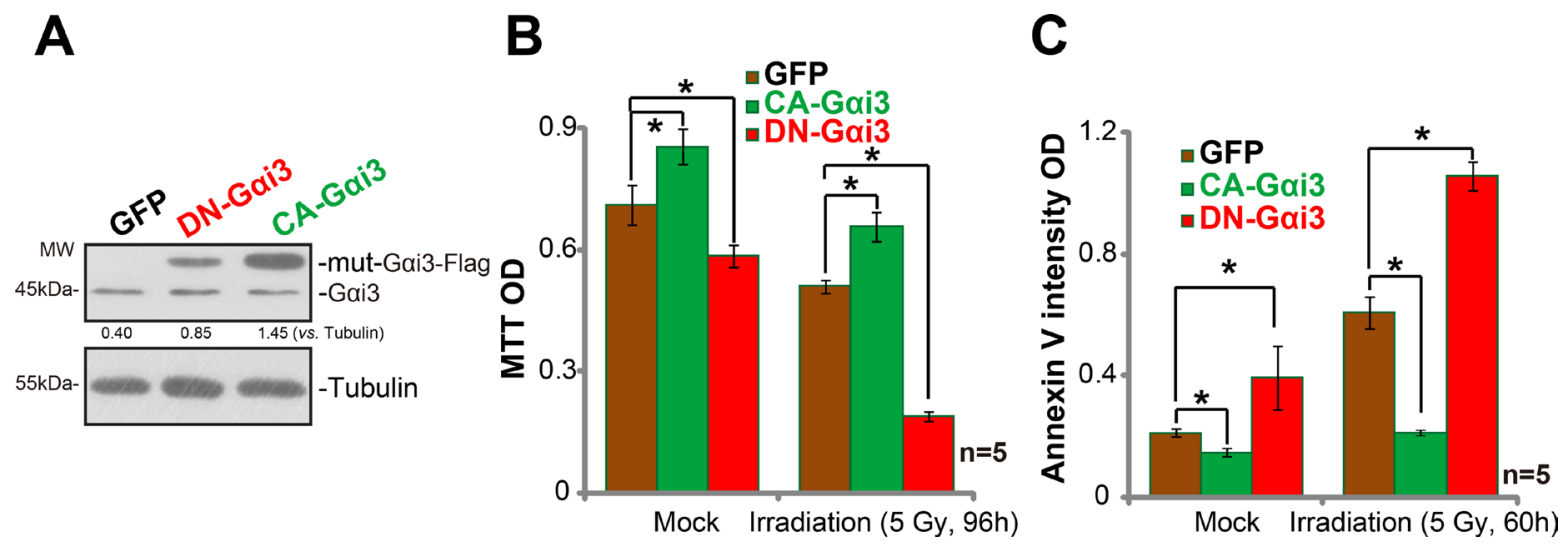

Figure 4: Irradiation sensitivity is altered with Gai3 mutation in A172 cells. Western blotting assay results showed expression of Gai3 (endogenous and mutant) in stable A172 cells with the dominant-negative Gai3 (G202T, "DN-Gai3"), the constitutively-active Gai3 (Q204L, "CA-Gai3”) or the empty vector (pGCL-GFP-puro, "GFP”) (A). Cells were also treated with irradiation (5 Gy) and cultured for indicated time; Cell death (MTT OD reduction, (B)) and apoptosis (Histone DNA ELISA assay, (C)) were tested. * $p<0.05$.

A $\quad$ A172

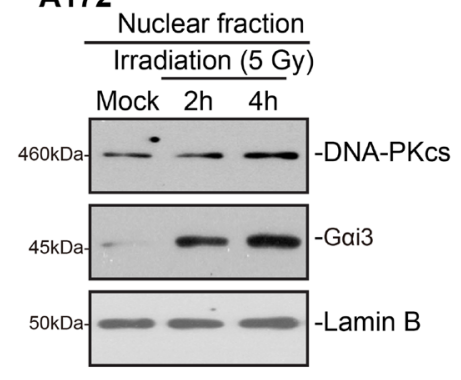

C

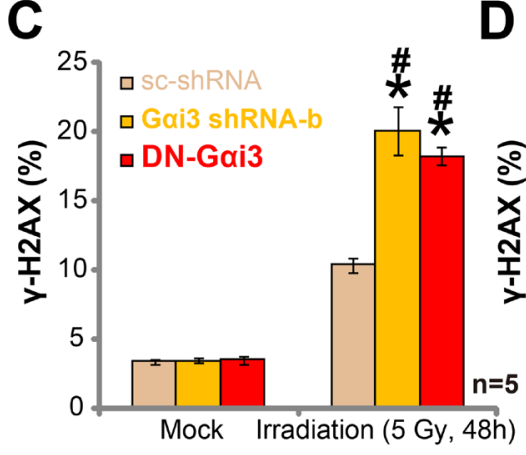

D
B

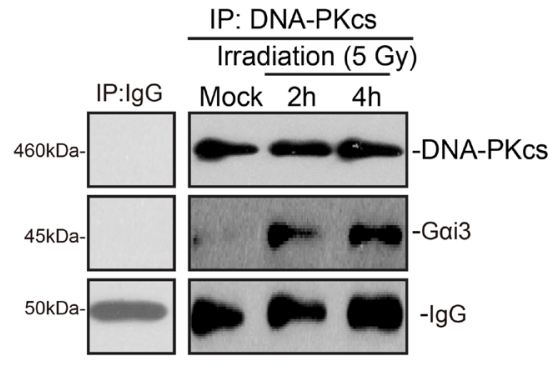

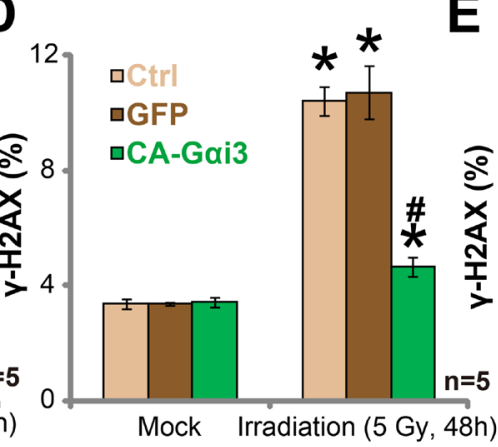

E

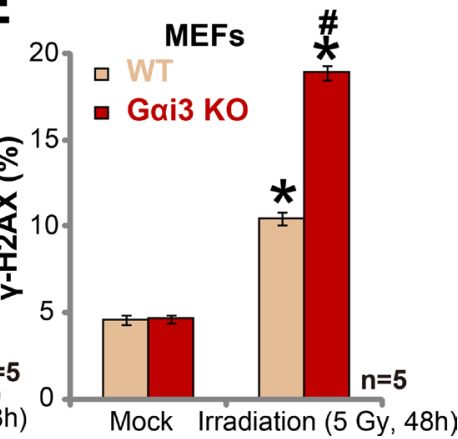

Figure 5: Irradiation induces Gai3 nuclear translocation and association with DNA-PKcs. A172 cells were treated with irradiation ( 5 Gy) for 2 and 4 hours, nuclear fractions were isolated, expression of listed protein was tested (A), Lamin-B is the nuclear marker protein). The association between DNA-PKcs and Gai3 in cell nuclei was tested by Co-IP assay (B). Stable A172 cells with scramble control shRNA ("scr-shRNA"), Gai3 shRNA ("-b"), the dominant-negative Gai3 (G202T, DN-Gai3) or the constitutively-active Gai3 (Q204L, CA-Gai3), as well as wild-type (WT) and Gai3 knockout (KO) MEFs, were treated with irradiation (5 Gy) and cultured for 48 hours, DNA damage was tested by $\gamma$-H2AX FACS assay, and $\gamma$-H2AX-postive cell ratio was recorded $(\mathbf{C}-\mathbf{E})$. * $p<0.05 v s$. "Mock". \# $p<0.05$ vs. "Irradiation" of "scr-shRNA" A172 cells (C), "GFP” A172 cells (D) or WT MEFs (E). 
to repair damaged DNA [28-30]. HR pathway is the second major pathway for DNA DSB repair [20-22]. After DNA damage, the Mre11/Rad50/Nbs1 (MRN) complex is recruited to the DNA ends, which then activates ATM and other DNA damage response proteins to repair broken DNA [30].

It is known that DNA-PKes is vital in the repair of damaged DNA by irradiation [21, 22, 24, 31, 23, 24]. DNA-PKcs is a phosphatidylinositol-3-kinase (PI3K)like protein kinase (PIKK) family kinase protein, which is activated following irradiation-induced DNA doublestrand breaks (DSBs) [23, 24]. DNA-PKcs silence, depletion or mutation will disrupt DNA repair mechanism, causing irradiation-sensitization $[21,22,24,31]$. On the other hand, over-expression and/or constitutive activation of DNA-PKcs could inhibit irradiation-induced DNA damage repair, leading to irradiation resistance [20, 30]. Indeed, DNA-PKcs expression is often elevated in glioma $[32,33]$ and other malignancies [34], and its upregulation in malignancy often correlates with irradiation resistance. Further studies suggest that DNA-PKcs expression level could be serve as a predictor for irradiation sensitivity in human cancer [35].

In the current study, we discovered an unique function of Gai3: Irradiation in A172 cells induced Gai3 translocation to nuclei, where it formed a complex with local protein DNA-PKcs. The complexation between Gai3 and DNA-PKcs was apparently crucial for DNA repair. Gai3 silence, depletion or dominant-negative mutation significantly potentiated irradiation-induced DNA damages. Reversely, expression of the constitutively-active Gai3 inhibited DNA damage by irradiation in A172 cells. Future studies will be needed to further explore the detailed mechanisms of Gai3's function in DNA damage repair.

\section{MATERIALS AND METHODS}

\section{Reagents}

All the antibodies of the current study were described previously [9, 10, 36, 37], and were provided by the Cell Signaling Tech (Shanghai, China) and Santa Cruz Biotech (Shanghai, China). The reagents for cell culture were purchased from Gibco (Shanghai, China). Puromycin was obtained from Sigma (Shanghai, China).

\section{Cell lines}

Wild-type (WT) and Gai3 knockout (KO) mouse embryonic fibroblasts (MEFs) were described previously [9-11]. Human glioma A172 cell line was purchased from the Cell Bank of Fudan University (Shanghai, China). Cells were cultured in routine DMEM medium, with 10\% fetal bovine serum (FBS) in the $\mathrm{CO}_{2}$ incubator.

\section{Irradiation}

Cells were irradiated with a $137 \mathrm{Cs}$ gamma rays source at a dose rate of $1.25 \mathrm{~Gy} / \mathrm{min}$ (MDS Nordion Gammacell Irradiator).

\section{Western blotting analysis}

Following the applied treatment, cells were lysed using the lysis buffer described [9, 10, 36]. Aliquots of $30 \mu \mathrm{g}$ of protein per treatment were separated by $7.5-10 \%$ SDS-PAGE gels, and were transferred to the PVDF membrane (Millipore, Bedford, MA). The membrane was then incubated with indicated primary antibody and corresponding second antibody. Antibody-antigen binding was detected by the ECL reagents (Amersham Biosciences). Each band was quantified through Image J software (NIH). Isolate of nuclei-localized proteins was described previously $[15,16]$. For all the Western blotting assay, each lane was loaded with exact same amount of quantified protein lysates (30 $\mu \mathrm{g}$ per sample). Same set of lysate samples were run in sister gels to test different proteins.

\section{Co-immunoprecipitation (Co-IP)}

The detailed protocol was described in our previous studies [9, 36]. Briefly, aliquots of $500 \mu \mathrm{g}$ of nucleilocalized protein lysates from each treatment were precleared with protein A/G beads ( $30 \mu \mathrm{L}$ per sample, Sigma). The pre-cleared lysate samples were then incubated with anti-DNA-PKcs antibody [38] overnight. Protein A/G beads (Sigma) were then added again, and the lysates were incubated for 2 hours at $4^{\circ} \mathrm{C}$. The beads were washed, and DNA-PKcs-Gai3 association was then detected by Western blotting assay.

\section{Gai3 shRNA}

The two lentiviral Gai3 shRNAs (“-a/-b”) were again purchased from Genechem (Shanghai, China), with the targeted sequences 5'-TCAATCATTCTCTTCCTTA3' (Gai3 shRNA-a) and 5'-CCTCAGTGATTATGACCTT3' (Gai3 shRNA-b), respectively. The lentiviral shRNA was added directed to the cells for 24 hours, puromycin (0. $5 \mu \mathrm{g} / \mathrm{mL}, 8$ days) was added to select the stable cells. Gai3 knockdown was confirmed by the Western blotting assay. Same amount of lentiviral scramble shRNA ("scrshRNA", Santa Cruz, sc-108080) was added to the control cells.

\section{Gai3 over-expression or mutation}

The wild-type Gai3 (-Flag), the constitutivelyactive-Gai3 (CA-Gai3-GFP-puro, Q204L), the dominant- 
negative Gai3 (DN-Gai3-GFP-puro, G202T), and the empty vector (pGCL-GFP-puro, GeneChem) were described previously [9-11]. The construct was transfected to A172 cells by Lipofectamine 2000 reagents [10]. After 24 hours, cells were subjected to puromycin $(0.5 \mu \mathrm{g} / \mathrm{mL}$, 8 days) selection. Expression of the target protein (Gai3) in stable cells was always tested by Western blotting assay.

\section{Cell growth, survival and apoptosis assay}

MTT assay of cell growth, clonogenicity assay of cell growth, and trypan blue staining of cell death, as well as Histone DNA apoptosis ELISA assay, Annexin V FACS assay of cell apoptosis and TUNEL nuclei staining assay of cell apoptosis were described in detail in our previous studies $[9,10,16,17,36,37,39,40,41]$.

\section{$\gamma$-H2AX FACS assay of cellular DNA damage.}

After irradiation, cells were trypsinized and fixed in ice-cold ethanol. Afterwards, cells were incubated with a mouse monoclonal anti- $\gamma-\mathrm{H} 2 \mathrm{AX}$ antibody (Cellular Signaling Tech, Shanghai, China) for 12 hours, and then incubated with a FITC-conjugated anti-mouse secondary antibody (Cell Signaling Tech). Cells were then subjected to FACS assay to determine $\gamma-\mathrm{H} 2 \mathrm{AX}$ percentage, which indicates DNA damage intensity [27].

\section{Statistical analysis}

The data were presented as means \pm standard deviation (SD) of one whole set of experiment. All experiments were repeated at least three times, with similar results obtained in each repeat. Statistical differences were analyzed by oneway ANOVA and multiple comparisons with the post hoc Bonferroni test (SPSS version 18.0). Values of $p<0.05$ were considered as statistically significant.

\section{CONCLUSIONS}

In summary, these results indicate a pivotal function of Gai3 in irradiation-resistance in human glioma cells. Gai3 could be a novel oncotarget for irradiation sensitization for glioma.

\section{Authors' contributions}

All the listed authors in the study carried out the experiments, participated in the design of the study and performed the statistical analysis, conceived of the study, and helped to draft the manuscript.

\section{ACKNOWLEDGMENTS AND FUNDING}

This work was generously supported by grants from the National Natural Science Foundation of China
(Nos. 81302195, 31371139, 81571282, 81502162, 81372411, 81172128); Grants from Natural Science Foundation of Jiangsu Province (BK20130301), and by the Graduate Scientific Research and Innovation Project of Soochow University, KYLX14_1267).

\section{CONFLICTS OF INTEREST}

The authors declare no conflicts of interests.

\section{REFERENCES}

1. Westphal M, Lamszus K. The neurobiology of gliomas: from cell biology to the development of therapeutic approaches. Nat Rev Neurosci. 2011; 12:495-508.

2. Siegel R, Naishadham D, Jemal A. Cancer statistics, 2012. CA Cancer J Clin. 2012; 62:10-29.

3. Siegel R, Ma J, Zou Z, Jemal A. Cancer statistics, 2014. CA Cancer J Clin. 2014; 64:9-29.

4. Khasraw M, Lassman AB. Neuro-oncology: late neurocognitive decline after radiotherapy for low-grade glioma. Nat Rev Neurol. 2009; 5:646-7.

5. Pollack IF. Neuro-oncology: Therapeutic benefits of reirradiation for recurrent brain tumors. Nat Rev Neurol. 2010; 6:533-5.

6. Wang $\mathrm{Y}$, Jiang $\mathrm{T}$. Understanding high grade glioma: molecular mechanism, therapy and comprehensive management. Cancer Lett. 2013; 331:139-46.

7. Watts C, Price SJ, Santarius T. Current concepts in the surgical management of glioma patients. Clin Oncol (R Coll Radiol). 2014; 26:385-94.

8. Alessi DR, James SR, Downes CP, Holmes AB, Gaffney PR, Reese CB, Cohen P. Characterization of a 3-phosphoinositide-dependent protein kinase which phosphorylates and activates protein kinase Balpha. Curr Biol. 1997; 7:261-9.

9. Cao C, Huang X, Han Y, Wan Y, Birnbaumer L, Feng GS, Marshall J, Jiang M, Chu WM. Galpha(i1) and Galpha(i3) are required for epidermal growth factor-mediated activation of the Akt-mTORC1 pathway. Sci Signal. 2009; 2:ra17.

10. Zhang YM, Zhang ZQ, Liu YY, Zhou X, Shi XH, Jiang Q, Fan DL, Cao C. Requirement of Galphai1/3-Gab1 signaling complex for keratinocyte growth factor-induced PI3K-AKT-mTORC1 activation. J Invest Dermatol. 2015; 135:181-91.

11. Li ZW, Cai S, Liu Y, Yang CL, Tian Y, Chen G, Cao C. Overexpression of Galphai3 in human glioma is required for AktmTOR activation and cell growth. Oncotarget. 2016 Aug 1. doi: 10.18632/oncotarget.10995. [Epub ahead of print].

12. Wang Z, Dela Cruz R, Ji F, Guo S, Zhang J, Wang Y, Feng GS, Birnbaumer L, Jiang M, Chu WM. G(i)alpha proteins exhibit functional differences in the activation of ERK1/2, Akt and mTORC1 by growth factors in normal and breast cancer cells. Cell Commun Signal. 2014; 12:10. 
13. Vink SR, Lagerwerf S, Mesman E, Schellens JH, Begg AC, van Blitterswijk WJ, Verheij M. Radiosensitization of squamous cell carcinoma by the alkylphospholipid perifosine in cell culture and xenografts. Clin Cancer Res. 2006; 12:1615-22.

14. Tu Y, Ji C, Yang B, Yang Z, Gu H, Lu CC, Wang R, Su ZL, Chen B, Sun WL, Xia JP, Bi ZG, He L. DNA-dependent protein kinase catalytic subunit (DNA-PKcs)-SIN1 association mediates ultraviolet B (UVB)-induced Akt Ser473 phosphorylation and skin cell survival. Mol Cancer. 2013; 12:172.

15. Zhang H, Liu YY, Jiang Q, Li KR, Zhao YX, Cao C, Yao J. Salvianolic acid A protects RPE cells against oxidative stress through activation of Nrf2/HO-1 signaling. Free Radic Biol Med. 2014; 69:219-28.

16. Li KR, Yang SQ, Gong YQ, Yang H, Li XM, Zhao YX, Yao J, Jiang Q, Cao C. 3H-1,2-dithiole-3-thione protects retinal pigment epithelium cells against Ultra-violet radiation via activation of Akt-mTORC1-dependent Nrf2-HO-1 signaling. Sci Rep. 2016; 6:25525.

17. Gong YQ, Huang W, Li KR, Liu YY, Cao GF, Cao C, Jiang Q. SC79 protects retinal pigment epithelium cells from UV radiation via activating Akt-Nrf2 signaling. Oncotarget. 2016; 7:60123-32. doi: 10.18632/oncotarget.11164.

18. Hubbard KB, Hepler JR. Cell signalling diversity of the Gqalpha family of heterotrimeric G proteins. Cell Signal. 2006; 18:135-50.

19. Barren B, Artemyev NO. Mechanisms of dominant negative G-protein alpha subunits. J Neurosci Res. 2007; 85:3505-14.

20. Roos WP, Thomas AD, Kaina B. DNA damage and the balance between survival and death in cancer biology. Nat Rev Cancer. 2016; 16:20-33.

21. Jeggo PA, Pearl LH, Carr AM. DNA repair, genome stability and cancer: a historical perspective. Nat Rev Cancer. 2016; 16:35-42.

22. Bunting SF, Nussenzweig A. End-joining, translocations and cancer. Nat Rev Cancer. 2013; 13:443-54.

23. Gao Y, Chaudhuri J, Zhu C, Davidson L, Weaver DT, Alt FW. A targeted DNA-PKcs-null mutation reveals DNA$\mathrm{PK}$-independent functions for $\mathrm{KU}$ in $\mathrm{V}(\mathrm{D}) \mathrm{J}$ recombination. Immunity. 1998; 9:367-76.

24. Falck J, Coates J, Jackson SP. Conserved modes of recruitment of ATM, ATR and DNA-PKcs to sites of DNA damage. Nature. 2005; 434:605-11.

25. Stiff T, O'Driscoll M, Rief N, Iwabuchi K, Lobrich $M$, Jeggo PA. ATM and DNA-PK function redundantly to phosphorylate $\mathrm{H} 2 \mathrm{AX}$ after exposure to ionizing radiation. Cancer Res. 2004; 64:2390-6.

26. Parsels LA, Morgan MA, Tanska DM, Parsels JD, Palmer BD, Booth RJ, Denny WA, Canman CE, Kraker AJ, Lawrence TS, Maybaum J. Gemcitabine sensitization by checkpoint kinase 1 inhibition correlates with inhibition of a Rad51 DNA damage response in pancreatic cancer cells. Mol Cancer Ther. 2009; 8:45-54.

27. Ewald B, Sampath D, Plunkett W. H2AX phosphorylation marks gemcitabine-induced stalled replication forks and their collapse upon S-phase checkpoint abrogation. Mol Cancer Ther. 2007; 6:1239-48.
28. Dungl DA, Maginn EN, Stronach EA. Preventing Damage Limitation: Targeting DNA-PKcs and DNA Double-Strand Break Repair Pathways for Ovarian Cancer Therapy. Front Oncol. 2015; 5:240.

29. Dobbs TA, Tainer JA, Lees-Miller SP. A structural model for regulation of NHEJ by DNA-PKcs autophosphorylation. DNA Repair (Amst). 2010; 9:1307-14.

30. Houtgraaf JH, Versmissen J, van der Giessen WJ. A concise review of DNA damage checkpoints and repair in mammalian cells. Cardiovasc Revasc Med. 2006; 7:165-72.

31. Convery E, Shin EK, Ding Q, Wang W, Douglas P, Davis LS, Nickoloff JA, Lees-Miller SP, Meek K. Inhibition of homologous recombination by variants of the catalytic subunit of the DNA-dependent protein kinase (DNA-PKcs). Proc Natl Acad Sci U S A. 2005; 102:1345-50.

32. Golding SE, Morgan RN, Adams BR, Hawkins AJ, Povirk LF, Valerie K. Pro-survival AKT and ERK signaling from EGFR and mutant EGFRvIII enhances DNA double-strand break repair in human glioma cells. Cancer Biol Ther. 2009; 8:730-8.

33. Yan D, Ng WL, Zhang X, Wang P, Zhang Z, Mo YY, Mao H, Hao C, Olson JJ, Curran WJ, Wang Y. Targeting DNAPKcs and ATM with miR-101 sensitizes tumors to radiation. PLoS One. 2010; 5:e11397.

34. Shintani S, Mihara M, Li C, Nakahara Y, Hino S, Nakashiro $\mathrm{K}$, Hamakawa H. Up-regulation of DNA-dependent protein kinase correlates with radiation resistance in oral squamous cell carcinoma. Cancer Sci. 2003; 94:894-900.

35. Noguchi T, Shibata T, Fumoto S, Uchida Y, Mueller W, Takeno S. DNA-PKcs expression in esophageal cancer as a predictor for chemoradiation therapeutic sensitivity. Ann Surg Oncol. 2002; 9:1017-22.

36. Cao C, Rioult-Pedotti MS, Migani P, Yu CJ, Tiwari R, Parang K, Spaller MR, Goebel DJ, Marshall J. Impairment of TrkB-PSD-95 signaling in Angelman syndrome. PLoS Biol. 2013; 11:e1001478.

37. Yang L, Zheng LY, Tian Y, Zhang ZQ, Dong WL, Wang XF, Zhang XY, Cao C. C6 ceramide dramatically enhances docetaxel-induced growth inhibition and apoptosis in cultured breast cancer cells: a mechanism study. Exp Cell Res. 2015; 332:47-59.

38. Zhen YF, Li ST, Zhu YR, Wang XD, Zhou XZ, Zhu LQ. Identification of DNA-PKcs as a primary resistance factor of salinomycin in osteosarcoma cells. Oncotarget. 2016; 7:79417-27. doi: 10.18632/oncotarget.12712.

39. Chen MB, Wei MX, Han JY, Wu XY, Li C, Wang J, Shen W, Lu PH. MicroRNA-451 regulates AMPK/mTORC1 signaling and fascin 1 expression in HT-29 colorectal cancer cells. Cell Signal. 2013.

40. Wu CH, Cao C, Kim JH, Hsu CH, Wanebo HJ, Bowen WD, Xu J, Marshall J. Trojan-horse nanotube on-command intracellular drug delivery. Nano Lett. 2012; 12: 5475-80.

41. Yao J, Bi HE, Sheng Y, Cheng LB, Wendu RL, Wang CH, Cao GF, Jiang Q. Ultraviolet (UV) and hydrogen peroxide activate ceramide-ER stress-AMPK signaling axis to promote retinal pigment epithelium (RPE) cell apoptosis. Int J Mol Sci. 2013; 14: 10355-68. 